\title{
Posterior Approach to Meckel's Cave: Retrosigmoid Craniectomy with Endoscopic Assistance
}

\author{
Paramita Das ${ }^{1}$ Hamid Borghei-Razavi ${ }^{2}$ Nina Z. Moore ${ }^{2}$ Pablo F. Recinos ${ }^{2}$
}

\author{
${ }^{1}$ Departmentof Neurosurgery, University of Chicago, Chicago, \\ Illinois, United States \\ 2 Department of Neurosurgery, Cleveland Clinic, Cleveland, Ohio, \\ United States
}

\begin{abstract}
Address for correspondence Paramita Das, MD, Department of Neurosurgery, Cleveland Clinic, 9500 Euclid Avenue, CA 51 Cleveland, OH 44195-5243, United States (e-mail: paramitadas05@gmail.com; dasxx092@umn.edu).
\end{abstract}

J Neurol Surg B 2019;80(suppl S3):S331-\$332.

\begin{abstract}
Keywords

- epidermoid

- Meckel's cave

- endoscopic assistance

- retrosigmoid

Background Meckel's cave involvement in tumors pose a challenge due to their surrounding neurovascular structure and deep location.

Case Review A 24-year-old male presented with progressive headaches and right sided trigeminal neuralgia with a large epidermoid. The tumor extended from the ambient cistern to the cerebellomedullary cistern and involved Meckel's cave (-Fig. 1). Technical Note/Video Description A retrosigmoid craniectomy was performed. Cranial nerves $3,4,6,7$, and 10, and auditory brainstem responses were monitored. Once the craniectomy was completed the dura was opened and cerebrospinal fluid (CSF) was released from the cisterna magna to allow for the tumor resection to be done without the use of any retractors (-Fig. 2). Care was taken to ensure that cranial nerves in the posterior fossa were detethered to prevent any traction injury. Using ring curettes the pearly white epidermoid tumor was able to be debulked. After all the possible tumor was resected with the microscope, the 30-degree endoscope was used to identify the porus trigeminus. Malleable ring curettes and a malleable suction were used to remove the soft tumor from this location. The patient transiently had loss of hearing but this returned within 2 weeks after surgery.

Conclusions The retrosigmoid approach is familiar to all neurosurgeons and with the adjunct of an angled endoscope, the posterior Meckel's cave can be easily reached. This is particularly useful for tumors with soft consistency. The assistance of the endoscope allows Meckel's cave visualization without additional drilling while still allowing safe resection of tumor from around the trigeminal nerve.

The link to the video can be found at: https://youtu.be/01aqOyUmSw0.
\end{abstract}

Conflict of Interest

None.

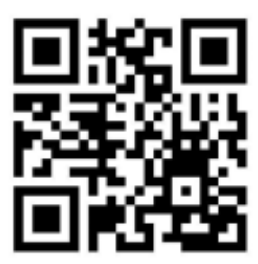

received

May 31, 2018

accepted after revision

November 11, 2018

published online

March 4, 2019

www.thieme.com/skullbasevideos

www.thieme.com/jnlsbvideos

DOI https://doi.org/

10.1055/s-0039-1677851. ISSN 2193-6331.
๑) 2019 Georg Thieme Verlag KG
Stuttgart · New York

License terms

(c) $(1) \ominus$ (\$) 


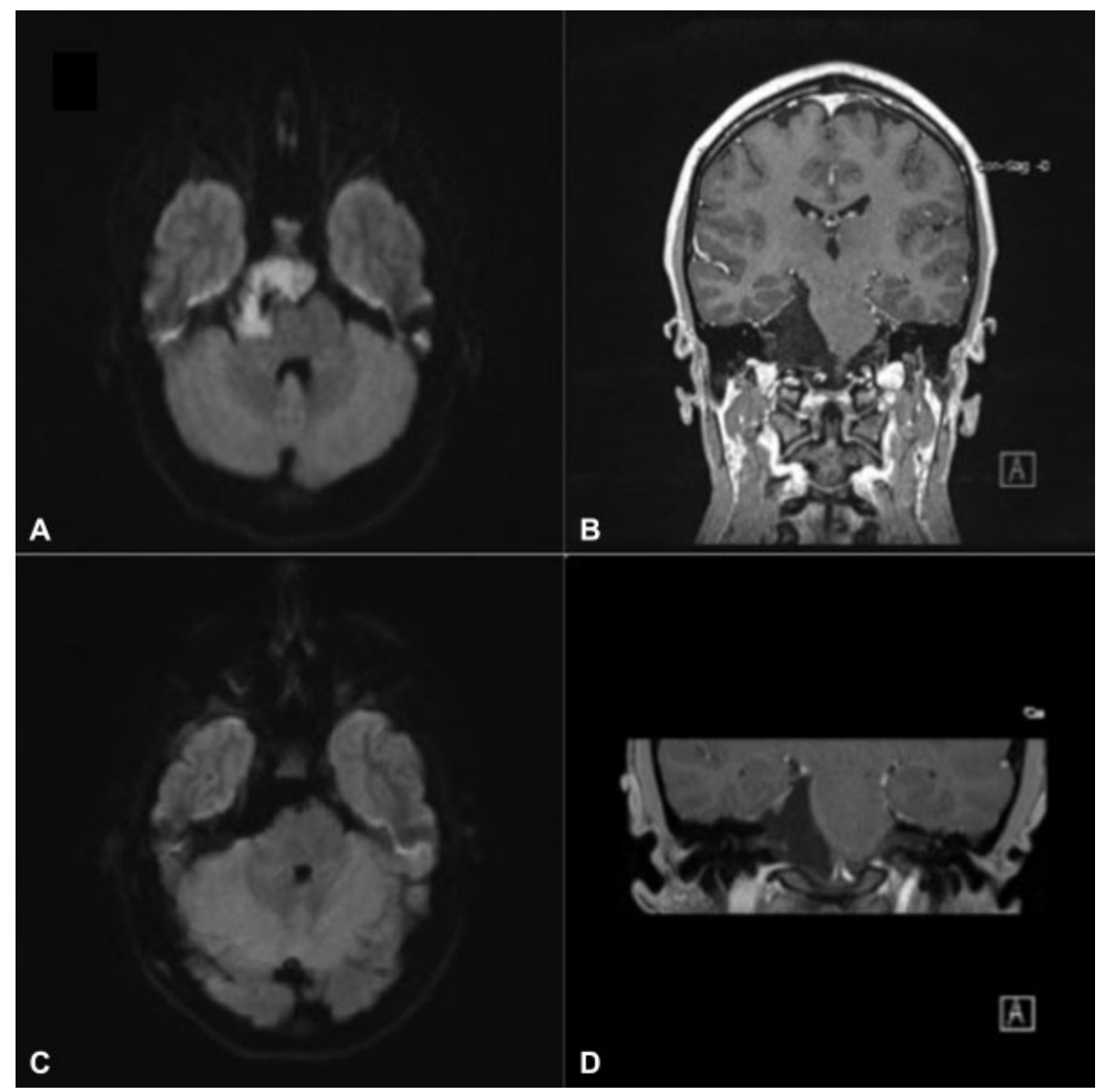

Fig. 1 (A) preoperative imaging showing diffusion restriction of epidermoid tumor; (B) preoperative post contrast imaging, showing the nonenhancing nature of epidermoid tumors; (C) postoperative imaging showing no further diffusion restriction in the prepontine cistern; (D) postoperative postcontrast imaging.

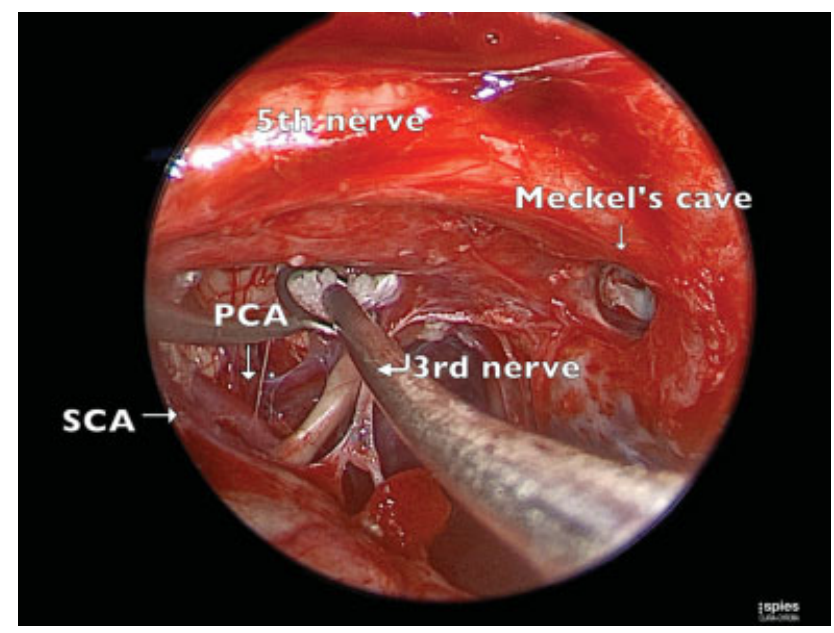

Fig. 2 endoscopic view from the retrosigmoid craniectomy. PCA, posterior cerebral artery; SCA, superior cerebellar artery. 